\title{
Preparation, characterization, and in vitro targeted delivery of folate-decorated paclitaxel-loaded bovine serum albumin nanoparticles
}

This article was published in the following Dove Press journal:

International Journal of Nanomedicine

10 September 2010

Number of times this article has been viewed

\section{Dongmei Zhao \\ Xiuhua Zhao \\ Yuangang $\mathrm{Zu}$ \\ Jialei Li \\ Yu Zhang \\ $\mathrm{Ru}$ Jiang \\ Zhonghua Zhang}

Key Laboratory of Forest Plant Ecology, Northeast Forestry University, Ministry of Education, Harbin, Heilongjiang, China
Correspondence: Yuangang Zu Key Laboratory of Forest Plant Ecology, Northeast Forestry University, Ministry of Education, Harbin, Heilongjiang 150040, China

Tel $+8645 I 82191517$

$\mathrm{Fax}+8645182102082$

Email zygorl@yahoo.com.cn

\begin{abstract}
Paclitaxel $\left(\mathrm{Taxol}^{\circledR}\right)$ is an important anticancer drug in clinical use for treatment of a variety of cancers. Because of its low solubility, it is formulated in high concentration in Cremophor $\mathrm{EL}^{\circledR}$ which induces hypersensitivity reactions. In this study, targeted delivery of paclitaxel-loaded nanoparticles was prepared by a desolvation procedure, crosslinked on the wall material of bovine serum albumin, and subsequently decorated by folic acid. The characteristics of the nanoparticles, such as amount of folate conjugation, surface morphology, drug entrapment efficiency, drug loading efficiency, and release kinetics were investigated in vitro. The targeting effect was investigated in vitro by cancer cell uptake of fluorescein isothiocyanate-labeled nanoparticles. The spherical nanoparticles obtained were negatively charged with a zeta potential of about $-30 \mathrm{mV}$, and characterized around $210 \mathrm{~nm}$ with a narrow size distribution. Drug entrapment efficiency and drug loading efficiency were approximately $95.3 \%$ and $27.2 \%$, respectively. The amount of folate conjugation was $9.22 \mu \mathrm{g} / \mathrm{mg}$ of bovine serum albumin. The folate-decorated nanoparticles targeted a human prostate cancer cell line effectively.
\end{abstract}

Keywords: paclitaxel, bovine serum albumin, folate, nanoparticles, target delivery

\section{Introduction}

Paclitaxel, a major anticancer drug isolated from the bark of Taxus brevifolia, has been used in the treatment of a wide variety of cancers. Because of its low solubility, its commercial formulation, Taxol $^{\circledR}$, is formulated in a high concentration in Cremophor $\mathrm{EL}^{\circledR}$, which induces hypersensitivity reactions. ${ }^{1}$ Another limitation of paclitaxel is its systemic toxicity, which causes severe adverse effects. ${ }^{2}$ Many approaches have been proposed, including micellar carriers, soluble polymers, paclitaxel-soluble prodrugs, and polymeric nanocapsules, in order to improve the therapeutic effects of paclitaxel and reduce its side effects. ${ }^{3-5}$

Drug-loaded nanoparticles with biodegradable carriers have the potential to provide an ideal solution for most of the major problems with anticancer drugs. Drug incorporation into nanoparticles follows a new concept to improve drug solubility, with a variety of advantages compared with standard paclitaxel therapy. ${ }^{6,7}$ Polymers have been used to develop paclitaxel-loaded nanoparticles, including an amphiphilic polymeric micelle of poly 2-(4-vinybenzyloxy0- $N, N$-diethylnicotinamide) (PDENA), PEG PEO-PLGA, cholesterol-grafted poly( $N$-isopropylacrylamide- $c o-N$, $N$-dimethylacrylamide-co-undecenoic acid) and poly( $\varepsilon$-caprolactone)/Poloxamer 188 (PCL/Poloxamer 188). ${ }^{8-11}$ 
Albumin is the most abundant protein in plasma $(35-50 \mathrm{~g} / \mathrm{L}$ human serum) with a molecular weight of $66.5 \mathrm{kDa}$, which is stable in the pH range of 4-9, soluble in $40 \%$ ethanol, and can be heated at $60^{\circ} \mathrm{C}$ for up to 10 hours without deleterious effects. These properties, as well as preferential uptake in tumor and inflamed tissue, ready availability, biodegradability, and lack of toxicity and immunogenicity make serum albumin an ideal candidate for drug delivery. Recent applications of serum albumin (human and bovine) have demonstrated some advantages as a natural and therefore biocompatible and biodegradable carrier for drugs. ${ }^{12-14}$ The albumin-based drug delivery system has increased the disease tissue/normal tissue drug concentration ratio. Nanoparticles of human serum albumin-bound paclitaxel (Abraxane, an example of nab $^{\mathrm{TM}}$ [nanometer albumin-bound] technology), have been approved by the Food and Drug Administration and a Phase III trial of a variety of cancer. ${ }^{15,16}$ Clinical studies have shown that nab-paclitaxel is significantly more effective than paclitaxel formulated as Cremophor $\mathrm{EL}^{\circledR}\left(\mathrm{CrEL}\right.$, Taxol ${ }^{\circledR}$, CrEL-paclitaxel), with almost double the response rate and increased time to disease progression. ${ }^{17}$

Specific targeting of tumor cells to achieve higher drug levels in tumor tissue and to minimize side effects is the major goal in cancer therapy. To achieve active targeting, nanoparticles should be equipped with functional molecules which can recognize and adhere to biomarkers on the surface of target cancer cells. Among targeting agents directed to membrane-bound tumor-associated receptors, folic acid has been widely utilized as a ligand for folate receptor-mediated selective targeting and delivery of drugs into tumor cells. ${ }^{18}$ The folate receptor has been found to be overexpressed in a wide range of tumors, and is known as a high-affinity membrane folate-binding protein, which mediates uptake of the vitamin by receptor-mediated endocytosis. ${ }^{19,20}$ Folate receptors exist in three major forms, ie, folate receptor- $\alpha$, folate receptor- $\beta$, and folate receptor- $\gamma$. The folate receptor- $\alpha$ form may be further qualified as a tumor-specific target overexpressed by many types of tumor cells, including those of the ovary, brain, kidney, breast, myeloid cells, and lung, because it generally becomes accessible to intravenous drugs only after malignant transformation. ${ }^{19}$ The role of folate receptors in the cellular transport of folate is not well understood, although a potocytosis (caveolin-coated endocytosis) model has been proposed. ${ }^{20}$ Recently, it has been reported that folate-mediated delivery of drug-loaded nanoparticles can enable binding, promote uptake, and have increased cytoxicity to cancer cells in vitro and in vivo. ${ }^{21-23}$
In the present study, the surfaces of paclitaxel-loaded biodegradable bovine serum albumin nanoparticles (PTXBSANPs) were modified by covalent attachment of folate to enable tumor cell-targeting ability. Characterization of the nanoparticles, including size and zeta potential, was carried out. Drug entrapment efficiency, drug loading efficiency, and release properties in vitro were also tested. The targeting effect of PTX-BSANPs with folate decoration (PTX-FA-BSANPs) was investigated in vitro by the uptake of fluorescence-labeled nanoparticles in PC3, a human prostate cancer cell line.

\section{Materials and methods Materials}

Folic acid, bovine serum albumin, trypsin, phosphate-buffered saline ( $\mathrm{pH} 7.4$ ), and fluorescein isothiocyanate were obtained from Sigma Aldrich, (St. Louis, MO). The paclitaxel was provided by Hisun Pharmaceutical Co. Ltd (Zhejiang, China). Ethanol and dichloromethane were used as analytic reagents. Methanol and cetonitrile were also used as analytic agents and were of high performance liquid chromatography grade. The water used was pretreated with the Milli-Q plus system (Millipore, Bedford, MA).

\section{Preparation of PTX-BSANPs with folate decoration}

The PTX-BSANPs were prepared as previously described using a desolvation technique. ${ }^{24,25}$ Bovine serum albumin was first dissolved in deionized water, a desolvating reagent. Paclitaxel dissolved in ethanol was added using a peristaltic pump TI/62/20 (Medorex, Norten-Hardenberg, Germany) at room temperature $(1 \mathrm{~mL} / \mathrm{min})$. Thereafter, $0.25 \%$ glutaraldehyde solution was added to crosslink the amino groups in the nanoparticles. The crosslinking process was performed during stirring of the suspension for 16 hours. The $\mathrm{pH}$ of the bovine serum albumin suspension was adjusted using $0.1 \mathrm{M}$ carbonate/bicarbonate buffer. The desolvating reagent was removed by evaporation using a rotary evaporator R201BL (SENCO, Shanghai, China) at $40^{\circ} \mathrm{C}$, and the nanoparticles were then redispersed in an ultrasonication bath TI-H-5 (Elma, Singen, Germany). The nanoparticles were collected by centrifugation at $16,000 \mathrm{~g}$ for 15 minutes (Sigma 3 K30, Harz, Germany), followed by washing twice with ethanol and deionized water. The suspension produced was freeze-dried for 48 hours using 5\% mannitol as the cryoprotectant to obtain a fine powder of nanoparticles.

We used the method for preparing N-hydroxysuccinimide ester of folate (NHS-folate) reported by Lee and Low. ${ }^{26}$ 
The carboxylic groups of NHS-folate were conjugated with the amino groups of the BSANPs under alkaline conditions ( $\mathrm{pH}$ 10.0). NHS-folate $5 \mathrm{mg}$ was dissolved in $0.1 \mathrm{M}$ carbonate/bicarbonate buffer $(\mathrm{pH} 10.0,1.0 \mathrm{~mL})$ and the stirred PTX-BSANPs suspension was added. This reaction took 12 hours. The unassociated NHS-folate in the mixture was then removed by dialyzing it against deionized water using Slide-A-Lyzer dialysis cassettes with a molecular weight cut-off of 3500 for 48 hours (Pierce, Rockford, IL), followed by freeze-drying, and the PTX-FA-BSANPs were obtained.

\section{Evaluation of folate conjugated with PTX-BSANPs}

The amount of folate that had been conjugated with the PTX-BSANPs was evaluated using the method described by Zhang. ${ }^{27}$ Briefly, after dialysis against deionized water, PTXFA-BSANPs ( $1 \mathrm{mg}$ in $1 \mathrm{~mL}$ deionized water) were digested by trypsin ( $0.05 \mathrm{mg} / \mathrm{mg}$ bovine serum albumin). The resulting tryptic hydrolysis of PTX-FA-BSANPs was scanning in the range $250-450 \mathrm{~nm}$ by ultraviolet spectrophotometer (Shimadzu, Tokyo, Japan) using tryptic hydrolysis of PTXBSANPs as a blank control. The extent of folate conjugated was determined relative to a folate reference: $y=0.0699 \times-0.0385$, $\mathrm{R}^{2}=0.999$ (y: absorption; $\mathrm{x}$ : folate concentration, $\mu \mathrm{g} / \mathrm{mL}$ ).

\section{Characterization of PTX-BSANPs with folate decoration}

Particle size and size distribution

Average particle size and size distribution of the nanoparticles were measured by laser light scattering (LLS, Zetaplus; Brookhaven Instruments, Holtsville, NY). The nanoparticles were diluted with deionized water and sonicated for several minutes before measurement.

\section{Surface charge}

The zeta potential of the PTX-FA-BSANPs was determined using a Zetaplus zeta potential analyzer (Brookhaven Instruments) at room temperature. The samples were prepared by diluting the nanoparticle suspension with deionized water. The data were obtained from the average of several measurements.

\section{Surface morphology}

The shape and surface morphology of PTX-BSANPs and PTX-FA-BSANPs were investigated by scanning electron microscopy (SEM, FEI Co., Eindhoven, The Netherlands).

\section{Physical status of paclitaxel and nanoparticles}

An X-ray diffractometer (Philips, Xpert-Pro, The Netherlands) was used to determine the physical status of paclitaxel in the nanoparticles. The diffraction angle $(2 \theta)$ was recorded from $3^{\circ}$ to $80^{\circ}$ with a scanning speed of $5^{\circ} /$ minute. CuKa radiation was used as the X-ray source at $40 \mathrm{kV}$ and $30 \mathrm{~mA}$.

\section{Drug encapsulation and loading efficiency}

The paclitaxel in ethanol was examined by high performance liquid chromatography, ie, a Waters liquid chromatograph (Waters Corporation, Milford, MA), consisting of a Waters 600 Controller equipped with a Waters 717 Plus autosampler, and a Waters 2487 UV detector. The samples were chromatographed at $25^{\circ} \mathrm{C}$ by injection of a $10 \mu \mathrm{L}$ sample into a Diamonsil $\mathrm{C} 18$ column, $250 \mathrm{~mm} \times 4.6 \mathrm{~mm} \times 5 \mu \mathrm{m}$ (Dikma Technologies, Beijing, China). The mobile phase was a mixture of methanol and acetonitrile in a volume ratio of 60:40 (v/v). The elution rate was $1.0 \mathrm{~mL} / \mathrm{min}$ and the paclitaxel wavelength was set at $227 \mathrm{~nm}$ (Supplementary Figure 1). The drug entrapment efficiency and drug loading efficiency were calculated using previously reported equations:

$$
\mathrm{DEE}=\frac{\mathrm{PTX}_{(\text {Total })}-\mathrm{PTX}_{\text {(in supernatant) }}}{\mathrm{PTX}_{(\text {Total })}}
$$$$
\mathrm{DLE}=\frac{\mathrm{PTX}_{(\text {Total })}-\mathrm{PTX}_{\text {(in supernatant) }}}{\text { PTX-FA-BSANPs }}
$$

\section{Drug release}

Paclitaxel release from the nanoparticles was determined in phosphate-buffered saline $(0.1 \mathrm{M}, \mathrm{pH} 7.4)$ at $37^{\circ} \mathrm{C}$. PTX-FABSANP suspension $(0.5 \mathrm{mg} / \mathrm{mL}, 2 \mathrm{~mL}$, without mannitol) was placed in Slide-A-Lyzer dialysis cassettes (MWCO 3500), and then the dialysis cassettes were immersed in a $250 \mathrm{~mL}$ beaker containing $200 \mathrm{~mL}$ release buffer. The beaker was placed in an incubator shaker at $37^{\circ} \mathrm{C}$ and $100 \mathrm{rpm}$. The release buffer $(100 \mathrm{~mL})$ was withdrawn from the beaker and replaced with $100 \mathrm{~mL}$ fresh release buffer at regular time intervals. The paclitaxel concentration in each collected release buffer sample was determined by high performance liquid chromatography. ${ }^{3}$

Paclitaxel was extracted from the removed medium after partitioning into the organic phase. Dichloromethane $6 \mathrm{~mL}$ was added to the medium, vortexed vigorously for five minutes, and left to stand for 15 minutes. Upon phase separation, the denser organic dichloromethane layer was carefully drip-separated from the aqueous buffer phase and allowed to evaporate at room temperature overnight. The dried sample containing 
paclitaxel was then dissolved in $2 \mathrm{~mL}$ of methanol and analyzed by high performance liquid chromatography. A profile showing cumulative drug release as a function of time was plotted. ${ }^{10}$ Each diffusion experiment was repeated in triplicate, and the mean values and standard deviations were calculated.

\section{Cell culture}

Human prostate cancer PC3 cells were cultured in folate-free RPMI 1640 medium containing $10 \%$ fetal calf serum and $0.1 \%$ antibiotics, at $37^{\circ} \mathrm{C}$ in a $5 \% \mathrm{CO}_{2}$ humidified atmosphere.

\section{Fluorescence microscopic images of nanoparticles}

For qualitative uptake studies, the cells were reseeded in six-well transparent plates. Cells were washed three times with cold phosphate-buffered saline after incubation with fluorescein isothiocyanate-labeled nanoparticles for four hours and 12 hours at $37^{\circ} \mathrm{C}$. Thereafter, cells were observed by confocal laser scanning microscopy (Nikon, Tokyo, Japan) with Fluoview imaging software.

\section{Results and discussion Characterization of PTX-BSANPs with folate decoration}

PTX-BSANPs prepared using the one-step desolvation technique of ethanol as the desolvating agent and glutaraldehyde as the crosslinking agent have been found to be highly stable in water and in cell medium. This method leads to the formation of least aggregated particles with a uniform distribution, and bovine serum albumin has been used in many studies as a delivery agent. ${ }^{23-25}$ Bovine serum albumin is a protein with an amino group and an acid group, so the process of nanoparticles crosslinking with glutaraldehyde might be affected by the $\mathrm{pH}$ of the medium. According to a report by Rahimnejad, ${ }^{14}$ particle size might be slightly influenced with a change of $\mathrm{pH}$ in the range of 170-210 nm. Sixty amino moieties in lysine residues and 26 arginine moieties in guanidine side chains, ${ }^{28} \mathrm{ie}$, about 10 percent of bovine serum albumin protein with 583 residues, might be solidified by a condensation reaction with a reagent containing an aldehyde group. As previously reported by Weber et $\mathrm{a}^{24}$ for desolvated human serum albumin particles, the lowest required glutaraldehyde concentration for the production of stable nanoparticles appears to be about $40 \%$. In our study, the glutaraldehyde concentration required for the production of stable nanoparticles was set up to $50 \%$. For the bovine serum albumin protein, about $90 \%$ of free amino residues could maintain protein function.
NHS-folate had three absorption maximum from 250 to $400 \mathrm{~nm}$, and the absorption peak of digested PTX-FABSANPs at $358 \mathrm{~nm}$ confirmed the successful conjugation of folate with BSANPs (Figure 1a). Moreover, according to the calibration curve of NHS-folate, 9.22 $\mu \mathrm{g}$ NHS-folate was conjugated with $1 \mathrm{mg}$ BSANPs.

The X-ray diffraction spectrum of paclitaxel and freeze-dried PTX-FA-BSANPs is shown in Figure 1b. The disappearance of the characteristic peak $\left(2 \theta=12.4^{\circ}\right)$ of paclitaxel in the PTX-FA-BSANPs suggested that paclitaxel was in an amorphous or disordered crystalline phase in the solid solution.

Average particle size and distribution of the nanoparticles were measured by laser light scattering. The PTX-FA-BSANPs
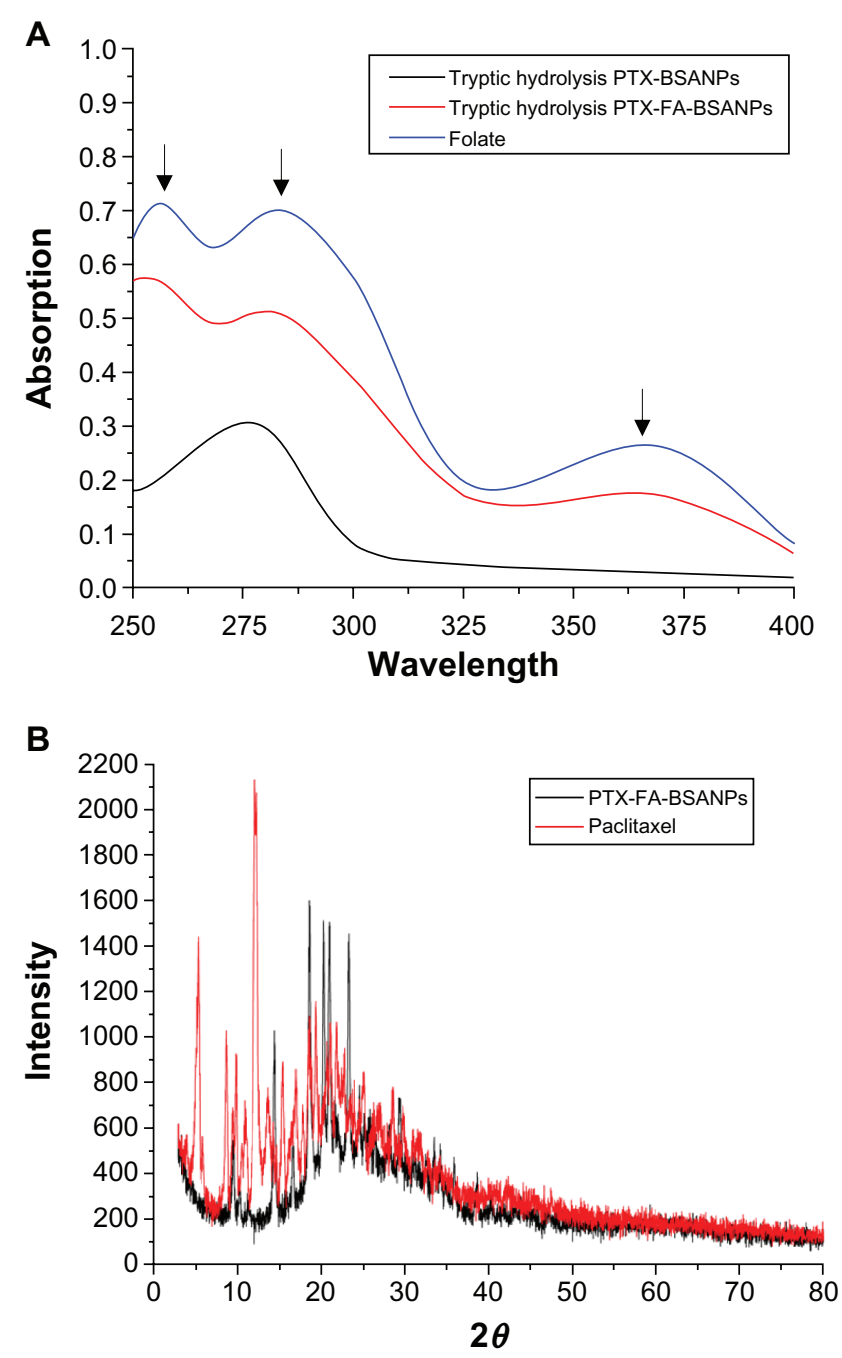

Figure I A) Determination of folate contents in PTX-FA-BSANPs. B) Physical status of paclitaxel and freeze-dried PTX-FA-BSANPs.

Abbreviation: PTX-FA-BSANPs, paclitaxel-loaded biodegradable bovine serum albumin nanoparticles with folate decoration. 
A

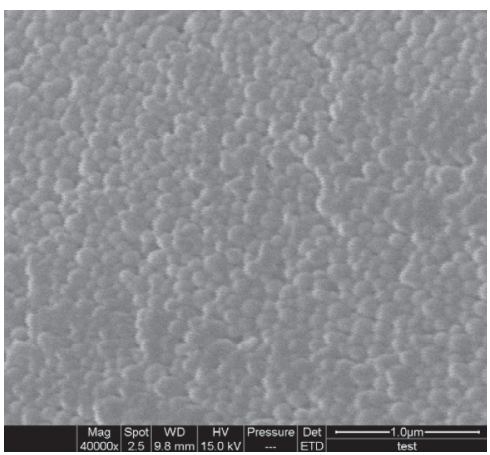

D

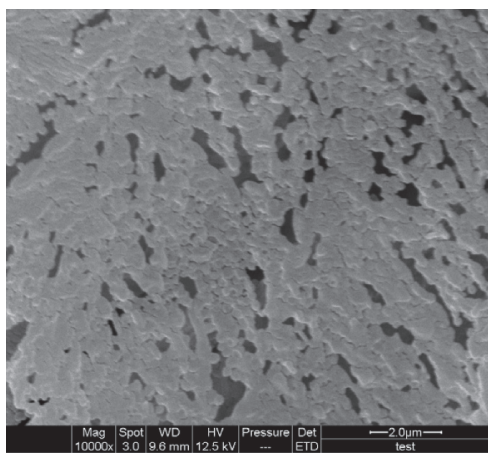

B

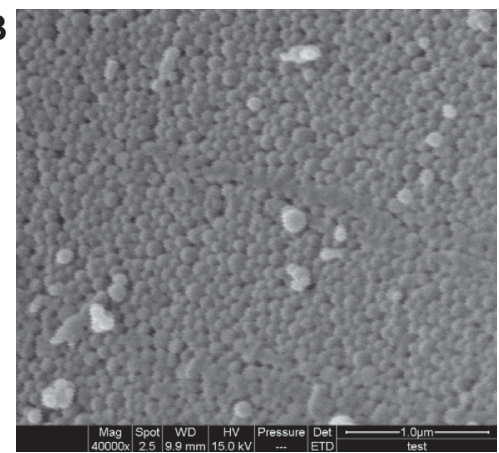

E

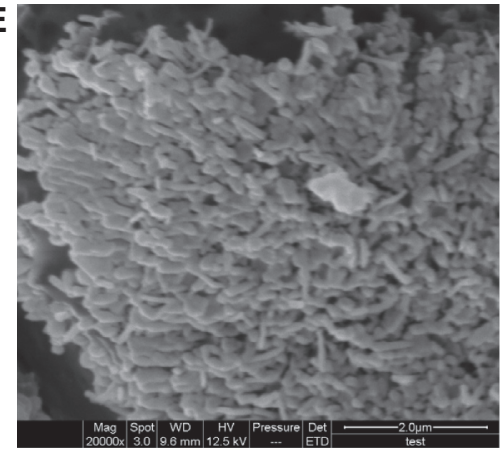

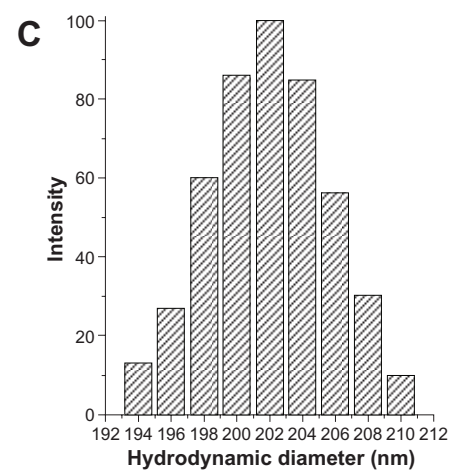

F

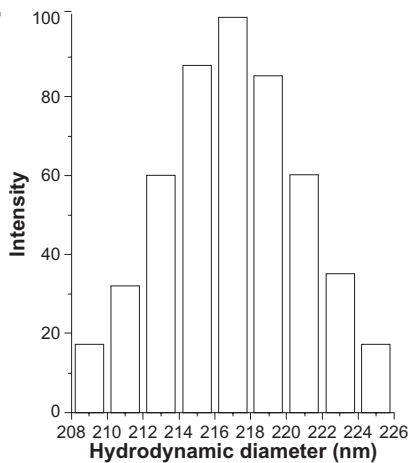

Figure 2 Characterization of PTX-BSANPs and PTX-FA-BSANPs. Scanning electron microscopic images of A) PTX-BSANPs. B) PTX-BSANPs with mannitol. D) PTXFA-BSANPs. E) PTX-FA-BSANPs with mannitol; particle polydispersity of C). PTX-BSANPs. F) PTX-FA-BSANPs obtained from laser light scattering.

Abbreviations: PTX-BSANPs, paclitaxel-loaded biodegradable bovine serum albumin nanoparticles; PTX-FA-BSANPs, paclitaxel-loaded biodegradable bovine serum albumin nanoparticles with folate decoration.

had an average size of $217.0 \pm 3.6 \mathrm{~nm}$ with a polydispersity of $0.034 \pm 0.004$ (Figure 2c). Comparing with PTX-BSANPs $(202.3 \pm 3.9 \mathrm{~nm}$, Figure 2f), the folate-decorated nanoparticles had the larger size.

Surface charge is an important indication of the stability of a colloidal nanoparticle system in medium. The repulsion among the nanoparticles with the same type of surface charge provides extra stability. The zeta potential of the PTX-FA-BSANPs indicated negative charges on the nanoparticle surface $(-30.91 \pm 1.97 \mathrm{mV})$, while that of PTX-BSANPs was around $-25 \pm 2.12 \mathrm{mV}$.

SEM was used to image the morphology of the PTXBSANPs and PTX-FA-BSANPs with and without mannitol (Figures 2a, 2b, 2d, and 2e). It was revealed by SEM imaging that the nanoparticles were generally spherical in shape with a narrow size distribution. Figures $2 \mathrm{~d}$ and $2 \mathrm{e}$ show the SEM images of nanoparticles freeze-dried with mannitol. Figure 3a shows the PTX-FA-BSANPs freeze-dried powder. The PTX-FABSANPs were well dispersed after adding mannitol. Moreover, no crystal precipitations were observed in PTX-FA-BSANP suspension (Figure 3b), which demonstrates the stability and applicability of the obtained drug delivery system.
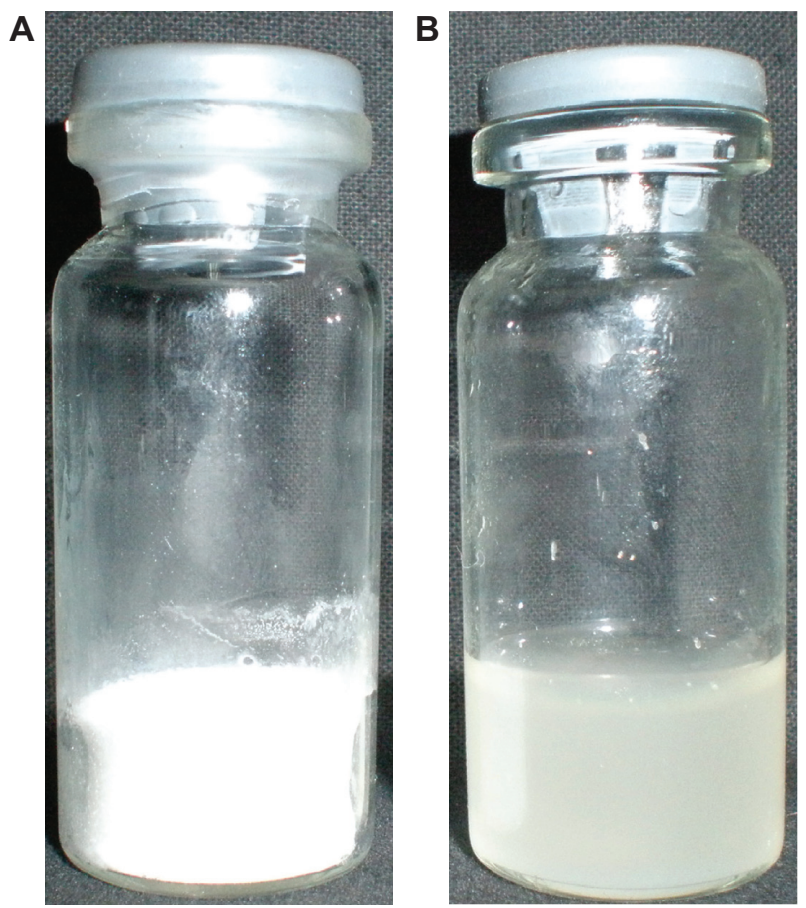

Figure 3 A) Freeze-dried powder. B) Reconstitution appearance of PTX-FABSANP solution.

Abbreviation: PTX-FA-BSANP, paclitaxel-loaded biodegradable bovine serum albumin nanoparticles with folate decoration. 


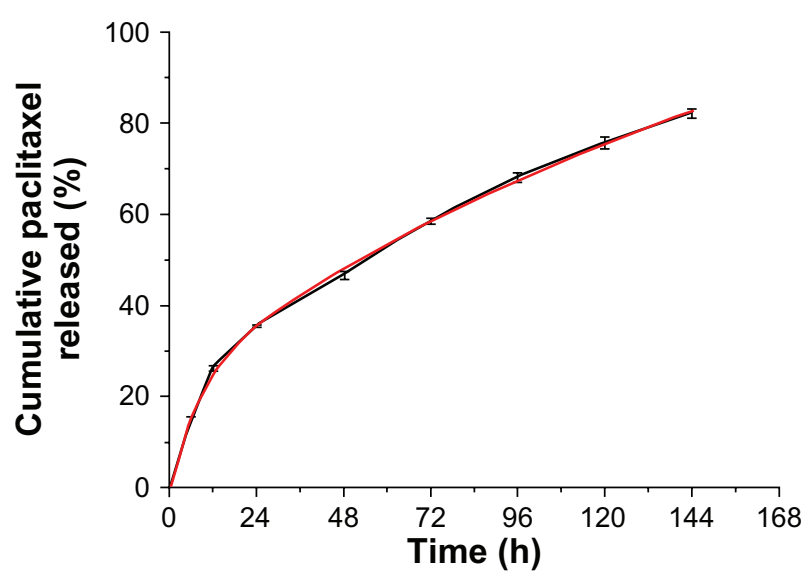

Figure 4 In vitro paclitaxel release profile from PTX-FA-BSANPs. Phosphate-buffered saline $(0.1 \mathrm{M}, \mathrm{pH}=7.4)$ was selected as the release medium. The nanoparticle dispersion was put in an orbital shaker and shaken at $120 \mathrm{rpm}$ at $37^{\circ} \mathrm{C}$. High performance liquid chromatography was performed to measure the released drug concentration. Abbreviation: PTX-FA-BSANP, paclitaxel-loaded biodegradable bovine serum albumin nanoparticles with folate decoration.

The bovine serum albumin concentration and quantities of ethanol and glutaraldehyde required, as well as the correct ratio of bovine serum albumin to paclitaxel, were investigated in the early research, ensuring high encapsulation and uniform particle size for the present study. The highest drug entrapment and loading efficiency achieved were 95.3\% and $27.2 \%$, respectively. At the loading level, the effective concentration of paclitaxel would be $285.6 \mathrm{mg} / \mathrm{L}$, which is already 910 times higher than its intrinsic water solubility of $0.3 \mathrm{mg} / \mathrm{L}$.

\section{In vitro drug release}

The in vitro drug release profiles of the PTX-FA-BSANPs over 144 hours are shown in Figure 4. An initial burst of $26.2 \%$ in the first 12 hours can be observed. In the following 36 hours, cumulative release reached $46.6 \%$, in a sustained manner, which provides the possibility to fight continually against cancer cells, resulting in decreased cancer cell viability. Cumulative release reached almost $85 \%$ after seven days and showed an almost released ability of the nanoparticle formulation. The in vitro drug release of PTXFA-BSANPs corresponded with the Higuichi equation of $y=-115.39 \mathrm{e}^{(-x / 202.35)}-24.39 \mathrm{e}^{(-x / 7.94)}+139.09\left(\mathrm{R}^{2}=99.9\right)$. The generally sustained and controlled release profile of paclitaxel facilitates the application of nanoparticles for the delivery of anticancer drugs.

The crosslinking process with glutaraldehyde plays a major role in the stability and drug release from the desolvated BSANPs. ${ }^{29}$ Compared with the slow release of paclitaxel, ${ }^{30}$ the continuous release of paclitaxel from the PTX-FA-BSANP solution scan be attributed to the solubilizing ability of the bovine serum albumin carrier. The erosion and degradation of BSANPs and the insolubility of paclitaxel in water were involved in the drug-release process.

\section{In vitro cellular uptake}

It has been demonstrated that the therapeutic effects of drugloaded nanoparticles depend on internalization and sustained retention of the nanoparticles by diseased cells. ${ }^{31}$ Although the in vitro and in vivo biologic processes could be very different, an in vitro investigation may provide some preliminary evidence to show the advantages of nanoparticles. Fluorescein isothiocyanate, a fluorescence marker, has been widely used as a probe for marking nanoparticles in cellular uptake experiments. $^{21,31}$ The cellular uptake of PTX-BSANPs and PTX-FA-BSANPs labeled by fluorescein isothiocyanate was examined to demonstrate internalization of the nanoparticles into cells and the targeting effects. Internalization of the nanoparticles was visualized by confocal laser scanning microscopy. In Figures 5b, 5c, and 5d, the fluorescence from the nanoparticles internalized in cells is shown. Figures $5 \mathrm{~b}$ and $5 \mathrm{c}$ show the images of the cells incubated for four hours with PTX-BSANPs and PTX-FA-BSANPs. A significant fluorescence difference between PTX-BSANPs and PTXFA-BSANPs can be observed. The PTX-FA-BSANPs were detected by the higher target effect. The results show that the folate-conjugated nanoparticles had better target delivery than nanoparticles without folate conjugation. When incubated for 12 hours with PTX-FA-BSANPs, the cells had been almost saturated by the fluorescence (Figure 5D). It is concluded that targeting of folate-decorated nanoparticles is significant and effective.

High-affinity folate-binding protein was characterized in the human prostate cancer cell line, and folic acid binds to the membrane fraction that crossreacts with the antiprostate-specific membrane antigen antibody. ${ }^{32}$ In PC-3 cells, folate receptor and antiprostate-specific membrane antigen mRNAs were not often observed by real-time polymerase chain reaction, while reduced folate carrier mRNA was present. ${ }^{33}$ An fluorescein isothiocyanate-labeled folate-bovine serum albumin conjugate was taken up by the prostate cancer cells, and the cellular association was significantly decreased in the presence of $1 \mathrm{mM}$ folic acid..$^{33}$ This result confirms the target effect detected in human prostate cancer cells in the study.

One important difference between bovine and human serum albumin is that bovine albumin has two tryptophan 
A

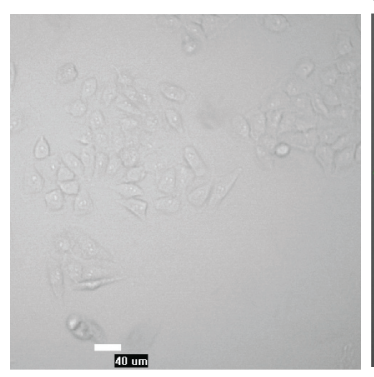

B

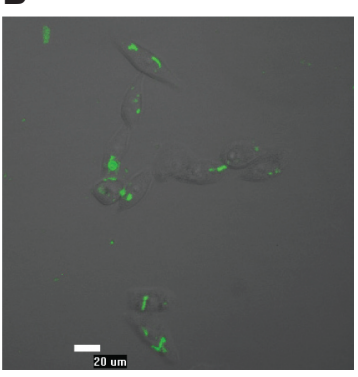

C

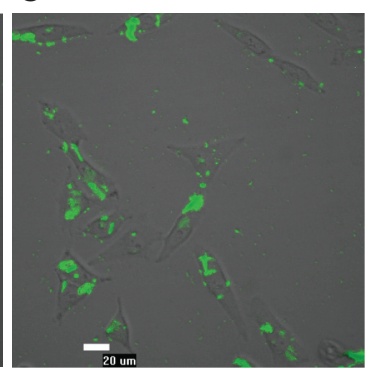

D

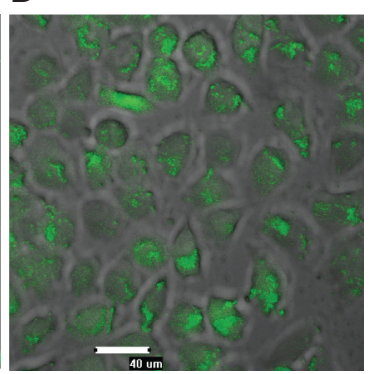

Figure 5 Confocal laser scanning microcopy images show the internalization of fluorescent nanoparticles in cells. A) Prostate cancer cells with no drug incubation. B) Prostate cancer cells incubated with PTX-BSANPs for four hours. C) Prostate cancer cells incubated with PTX-FA-BSANPs for four hours. D) Prostate cancer cells incubated with PTX-FA-BSANPs for 12 hours.

Abbreviations: PTX-BSANP, paclitaxel-loaded biodegradable bovine serum albumin nanoparticles; PTX-FA-BSANP, paclitaxel-loaded biodegradable bovine serum albumin nanoparticles with folate decoration.

residues while human albumin has a unique tryptophan, although they have a similar folding, a well known primary structure. The PTX-BSANPs prepared in this study had a similar function to human serum albumin-bound paclitaxel prepared by high-pressure homogenization, and were also detected in similar target lesion as that of human serum albumin-bound paclitaxel. Two transport pathways for human serum albumin-bound paclitaxel has been proposed. Albumin paclitaxel molecules bind to an albumin receptor (gp60), which cluster on endothelial surfaces and associates with caveolin-1, which transports the hydrophobic paclitaxel into the extravascular space. ${ }^{34,35}$ A second proposed transport pathway for the nanoparticle is via secreted protein acidic and rich in cysteine (SPARC). SPARC protein can bind albumin and can increase the concentration of the albuminbound paclitaxel particle in the tumor due to such binding. ${ }^{6}$ The transport mechanism of human serum albumin-bound paclitaxel could be used to explain the target effect of PTXBSANPs detected in our study.

\section{Conclusion}

In this study, nanoparticles of folate-conjugated waterinsoluble paclitaxel-loaded bovine serum albumin have been successfully synthesized and characterized by a desolvation technique. The nanoparticles showed natural property, high stability, desired surface properties in favor of cellular uptake and can be targeted specifically to cancer cells. The water solubility of paclitaxel increased significantly. It should be pointed out that this is only a proof-of-concept investigation. Bovine serum albumin would be substituted by human serum albumin in further experiments in order to avoid a possible immunologic response in vivo. In vitro cytosis and in vivo investigation should now be undertaken to collect sufficient data for the clinical application of paclitaxel-loaded nanoparticles.

\section{Acknowledgments}

This research was supported by the National Key Technology R and D Program (2006BAD18B0401) and the Fundamental Research Funds for the Central Universities (41409202). The authors express their gratitude to Yongzhi Cui for conducting the SEM analysis.

\section{Disclosure}

The authors report no conflict of interest in this work.

\section{References}

1. Szebeni J, Muggia FM, Alving CR. Complement activation by cremophor EL as a possible contributor to hypersensitivity to paclitaxel: An in vitro study. J Natl Cancer Inst. 1998;90(4):300-306.

2. Michaud LB, Valero V, Hortobagyi G. Risks and benefits of taxanes in breast and ovarian cancer. Drug Saf. 2000;23(5):401-428

3. Dosio F, Brusa P, Crosasso P, Arpicco S, Cattel L. Preparation, characterization and properties in vitro and in vivo of a paclitaxelalbumin conjugate. J Control Release. 1997;47(3):293-304.

4. Skwarczynski M, Hayashi Y, Kiso Y. Paclitaxel prodrugs: Toward smarter delivery of anticancer agents. J Med Chem. 2006;49(25) 7253-7269.

5. Marupudi NI, Han JE, Li KW, et al. Paclitaxel: A review of adverse toxicities and novel delivery strategies. Expert Opin Drug Saf. 2007; 6(5):609-621.

6. Desai N, Teieu V, Yao Z, et al. Increased antitumor activity, intratumor paclitaxel concentrations, and endothelial cell transport of cremophor-free, albumin-bound paclitaxel, ABI-007, compared with cremophor-based paclitaxel. Clin Cancer Res. 2006;12(4): 1317-1324.

7. Gradishar WJ, Tjulandin S, Davodson N, et al. Phase III trial of nanoparticle albumin-bound paclitaxel compared with polyethylated castor oil-based paclitaxel in women with breast cancer. J Clin Oncol. 2005;23(31):7794-7803

8. Huh KM, Lee SC, Cho YW, Lee J, Jeong JH, Park K. Hydrotropic polymer micelle system for delivery of paclitaxel. $J$ Control Release 2005;101(1-3):56-68

9. Suh H, Jeong B, Rathi R, Kim SW. Regulation of smooth muscle cell proliferation using paclitaxel-loaded poly(ethylene oxide)poly(lactide/glycolide) nanospheres. J Biomed Mater Res. 1998;42(2): 331-338.

10. Seow WY, Xue JM, Yang YY. Targeted and intracellular delivery of paclitaxel using multi-functional polymeric micells. Biomaterials. 2007;28(9):1730-1740. 
11. Zhang Y, Tang L, Sun L, et al. A novel paclitaxel-loaded poly( $\varepsilon$-caprolactone)/Poloxamer 188 blend nanoparticle overcoming multidrug resistance for cancer treatment. Acta Biomater. 2010;6(6): 2045-2052.

12. Temming K, Meyer DL, Zabinski R, et al. Evaluation of RGD-targeted albumin carriers for specific delivery of auristatin $\mathrm{E}$ to tumor blood vessels. Bioconjug Chem. 2006;17(6):1385-1394.

13. Temming K, Meyer DL, Zabinski R, et al. Improved efficacy $\alpha v \beta 3$ targeted albumin conjugates by conjugation of a novel auristatin derivative. Mol Pharm. 2007;4(5):686-694.

14. Rahimnejad M, Jahanshahi M, Najafpour GD. Production of biological nanoparticles from bovine serum albumin for drug delivery. Afr $J$ Biotechnol. 2006;5(20):1918-1923.

15. Green MR, Manikhas GM, Orlov S, Afanasyev B. Makhson AM. Abraxane $^{\circledR}$, a novel Cremophor ${ }^{\circledR}$-free, albumin-bound particle form of paclitaxel for the treatment of advanced non-small-cell lung cancer. Ann Oncol. 2006;17(8):1263-1268.

16. Miele E, Spinelli GP, Miele E, Tomao F, Tomao S. Albumin-bound formulation of paclitaxel (Abraxane ${ }^{\circledR} \mathrm{ABI}-007$ ) in the treatment of breast cancer. Int J Nanomedicine. 2009;4:99-105.

17. Gradishar WJ. Albumin-bound paclitaxel: A next-generation taxane. Expert Opin Pharmacother. 2006;7(8):1041-1053.

18. Gruner BA, Weitman SD. The folate receptor as a potential therapeutic anticancer target. Invest New Drugs. 1999;16(3):205-219.

19. Lu Y, Low PS. Folate-mediated delivery of macromolecular anticancer therapeutic agents. Adv Drug Deliv Rev. 2002;54(5):675-693.

20. Sabharanjak S, Mayor S. Folate receptor endocytosis and trafficking. Adv Drug Deliv Rev. 2004;56(8):1099-1109.

21. Zheng Y, Song SG, Darby M, et al. Preparation and characterization of folate-poly(ethylene glycol)-grafted-trimethylchitosan for intracellular transport of protein through folate receptor-mediated endocytosis. J Biotechnol. 2009;145(1):47-53.

22. Dosio F, Arpico S, Stella B, Brusa P, Cattel L. Folate-mediated targeting of albumin conjugates of paclitaxel obtained through a heterogeneous phase system. Int J Pharm. 2009;382(1-2):117-123.

23. Li FQ, Su H, Wang J, Liu YJ, et al. Preparation and characterization of sodium ferulate entrapped bovine serum albumin nanoparticles for live targeting. Int J Pharm. 2008;349(1-2):274-282.
24. Weber C, Coester C, Keruter J, Langer K. Desolvation process and surface characterization of protein nanoparticles. Int J Pharm. 2000;194(1):91-102.

25. Zu Y, Zhang Y, Zhao X, Zhang Q, Liu Y, Jiang R. Optimization of the preparation process of vinblastine sulfate (VBLS)-loaded folate conjugated bovine serum albumin (BSA) nanoparticles for tumortargeted drug delivery using response surface methodology (RSM). Int J Nanomedicine. 2009;4:321-333.

26. Lee R, Low P. Delivery of liposomes into cultured KB cells via folate receptor mediated endocytosis. J Biol Chem. 1994;269(5): 3198-3204.

27. Zhang L, Hou S, Mao S, Wei D, Song X, Lu Y. Uptake of folate-conjugated albumin nanoparticles to the SKOV3 cells. Int $J$ Pharm. 2004;287(1-2):155-162.

28. Meziani MJ, Sun YP. Protein-conjugated nanoparticles from rapid expansion of supercritical fluid solution into aqueous solution. $\mathrm{J} \mathrm{Am}$ Chem Soc. 2003;125(26):8015-8018.

29. Merodio M, Arnedo A, Renedo MJ, Irache JM. Ganciclovir-loaded albumin nanoparticles: Characterization and in vitro release properties. Eur J Pharm Sci. 2001;12(3):251-259.

30. Cho WY, Lee J, Lee SC, Huh KM, Park K. Hydrotropic agents for study of in vitro paclitaxel release from polymeric micelles. J Control Release. 2004;97(2):249-257.

31. Hattori Y, Maitani Y. Enhanced in vitro DNA transfection efficiency by novel folate-linked nanoparicles in human prostate cancer and oral cancer. J Control Release. 2004;97(1):173-183.

32. Holm J, Hansen SI, Hoier-Madsen M. High-affinity folate binding in human prostate. Biosci Rep. 1993;13(2):99-105.

33. Hattori Y, Maitani Y. Folate-linked nanoparticle-mediated suicide gene therapy in human prostate cancer and nasopharyngeal cancer with herpes simplex virus thymidine kinase. Cancer Gene Ther. 2005; 12(10):796-809.

34. Paal K, Muller J, Hegedus L. High affinity binding of paclitaxel to human serum albumin. Eur J Biochem. 2001;268(7):2187-2191.

35. Haley B, Frenkel E. Nanoparticles for drug delivery in cancer treatment. Urol Oncol. 2008;26(1):57-64. 


\section{Supplementary figure}

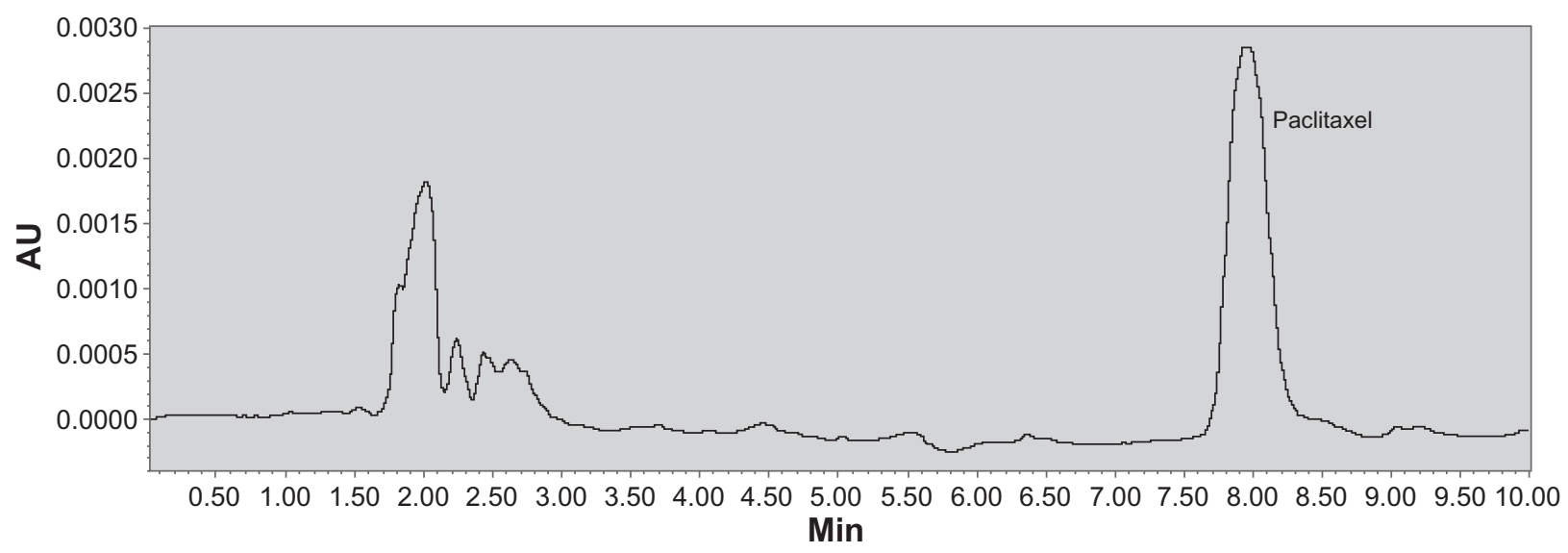

Figure SI Chromatograph profile of paclitaxel by high performance liquid chromatography.

\section{Publish your work in this journal}

The International Journal of Nanomedicine is an international, peerreviewed journal focusing on the application of nanotechnology in diagnostics, therapeutics, and drug delivery systems throughout the biomedical field. This journal is indexed on PubMed Central, MedLine, CAS, SciSearch $\AA$, Current Contents ${ } /$ Clinical Medicine,
Journal Citation Reports/Science Edition, EMBase, Scopus and the Elsevier Bibliographic databases. The manuscript management system is completely online and includes a very quick and fair peer-review system, which is all easy to use. Visit http://www.dovepress.com/ testimonials.php to read real quotes from published authors. 